\title{
Using synthetic semiochemicals to train canines to detect bark beetle-infested trees
}

\author{
Annette Johansson $^{1,2} \cdot$ Göran Birgersson ${ }^{1}$ (i) $\cdot$ Fredrik Schlyter $^{1,3}$ (i) \\ Received: 10 December 2018 / Accepted: 23 April 2019 /Published online: 29 May 2019 \\ (C) The Author(s) 2019
}

\begin{abstract}
- Key message The dog detection allows timely removal by sanitation logging of first beetle-attacked trees before offspring emergence, preventing local beetle increases. Detection dogs rapidly learned responding to synthetic bark beetle pheromone components, with known chemical titres, allowing search training during winter in laboratory and field. Dogs trained on synthetics detected naturally attacked trees in summer at a distance of $>100 \mathrm{~m}$.

- Context An early detection of first beetle-attacked trees would allow timely sanitation felling before offspring emergence, curbing local beetle increase.

- Aims We tested if detection dogs, trained off-season on synthetic pheromone components from Ips typographus, could locate naturally bark beetle-infested spruce trees.

- Methods Indoor training allowed dogs to discriminate between the infestation odours (target) and natural odours (non-target) from the forest. Odour stimuli were shown by chemical analysis to be bioactive at extremely low-levels released $\left(<10^{-4} \mathrm{ng} /\right.$ $15 \mathrm{~min}$ ) in the laboratory.

- Results Detection dogs, trained to recognise four different synthetic pheromone compounds in the wintertime, were able to detect naturally infested spruce trees unknown to humans the following summer. The dog-handler pairs were able to detect an infested spruce tree from the first hours of beetle attack until several weeks after first attack, long before discolouration of the crown. Trained sniffer dogs detected infested spruce trees out to $\geq 100 \mathrm{~m}$, as measured by GPS-collar tracks.

- Conclusion Dog-handler pairs appear to be more efficient than humans alone in timely detecting bark beetle infestations due to the canine's ability to cover a greater area and detect by olfaction infestations from a far longer distance than can humans.
\end{abstract}

Keywords Ips typographus · Gas chromatography-mass spectrometry extracted ion chromatograms $\cdot$ Detection dog $\cdot$ Sanitation logging $\cdot$ Forest protection $\cdot$ Norway spruce

Handling Editor: Aurélien Sallé

Contribution of the co-authors AJ and FS designed research; AJ and GB collected data; AJ, GB, and FS analysed data; all authors contributed to the writing process. All authors read and approved the submitted version.

Fredrik Schlyter

fredrik.schlyter@slu.se

1 Department of Plant Protection Biology, Swedish University of Agricultural Sciences, PO Box 102, SE-230 53 Alnarp, Sweden

2 SnifferDogs Sweden, Bäckvägen 26, SE-342 93 Hjortsberga, Sweden

3 Present address: Excellent Team for Mitigation, Faculty of Forestry \& Wood Science, Czech University of Life Sciences Prague, Kamycka 129, 16521 Prague 6, Czech Republic

\section{Introduction}

Detection dogs are used to locate many objects including humans, explosives, and illicit drugs (see Browne et al. 2006 and references therein; Lorenzo et al. 2003). Trained canines have also been used to detect invasive organisms (Goodwin et al. 2010; Hoyer-Tomiczek et al. 2016) as well as endangered species (reviewed by Beebe et al. 2016). Canines have also been trained to detect small or cryptic insects such as termites (Brooks et al. 2003), palm weevils (Nakash et al. 2000; Suma et al. 2014), bed bugs (Pfiester et al. 2008; Vaidyanathan and Feldlaufer 2013), and endangered Coleoptera (Mosconi et al. 2017). The key benefits of using trained detection dogs are their keen sense of smell (Hepper and Wells 2015) and their ability to cover large areas in a shorter time when compared with humans (Mosconi et al. 
2017). In most cases, biological material is used for the training (Johnen et al. 2013).

The European spruce bark beetle-Ips typographus (L.) is one of the most destructive forest pests in Europe (Grégoire and Evans 2004). For forest protection, the rapid detection of bark beetle infestations is required to successfully implement a management strategy that relies upon removing recently infested trees within 2-3 weeks of attack (Svensson 2007). However, human detection generally requires close inspection $(\leq 1 \mathrm{~m})$ of trees and is therefore time-consuming, costly, and not always practical. Therefore, detection generally occurs $2-$ 3 months after an infestation in north Europe, when tree crown colour fades and bark falls off. By this time, most bark beetles have left the infested tree and may attack other, non-infested trees. Since a rapidly changing, but specific series of beetle pheromone components and other semiochemicals are present for several weeks after an initial attack, the use of detection dogs may prove a better alternative than human inspection. Upon attacking a tree, male bark beetles secret an aggregation pheromone, consisting of a blend of 2-methyl-3-buten-2-ol and cis-verbenol (Birgersson et al. 1984). A few days later, an inhibitory signal (consisting mainly of ipsdienol) is emitted when bark beetle females have begun laying eggs (Birgersson et al. 1984; Schlyter et al. 1987). After the first week, an additional chemical cue, indicating that the infested tree is fully utilised and competition is high, is evident. This semiochemical, verbenone, is an oxygenation product by the beetle and by the interaction of fungi and bacteria with damaged tree phloem (Leufvén and Birgersson 1987; Schlyter et al. 1989).

In this proof of concept study, we tested if rapid laboratory training of detection dogs on a series of synthetic semiochemicals associated with bark beetle infestations would allow these trained dogs to later detect and locate bark beetleinfested trees of different ages in the field. Since the semiochemical profile of attacked trees changes rapidly in both the quality and quantity of semiochemicals released over several weeks (above), we chose to use four synthetic chemical compounds as stimuli, representing the four major cues emitted over the weeks of insect attack, in our canine training. We hypothesised that dogs field-trained on this series of synthetic pheromones in the winter months could later locate infested trees from several weeks past in the summer months. Finally, we tested the hypothesis that a trained dog can detect natural infestations from distances further away than a human can (10 to 100 times).

\section{Materials and methods}

\subsection{Canines}

Two dogs, owned by SnifferDogs Sweden (Hjortsberga, Sweden), were used in this study. Dog A was a 9-year-old female German shepherd that previously trained as a search and rescue dog for humans. Dog B was a 1-year-old female Belgian shepherd (Malinois) that had only basic obedience training and had no previous formal detection expertise.

\subsection{Chemicals}

Synthetic bark beetle pheromones used in this study included methylbutenol (2-methyl-3-buten-2-ol; Acros Organics, Gothenburg, Sweden), 4S-cis-verbenol (Borregard, Sarpsborg, Norway), and ipsdienol (ICN/MP Biomedicals, USA). Synthetic verbenone, a bark beetle pheromone and a product of the host tree, was obtained from Fluka (SigmaAldrich, Stockholm, Sweden). Other chemicals used in the study were obtained from our chemical stocks (see Andersson et al. 2012).

Each pheromone component was stored separately in separate jars of glass to avoid cross-contamination of odours. In each jar of glass, a cotton pad (ICA Basic Bomullsrondeller, Netherlands) was placed in the bottom and a small amount of each semiochemical was dropped on to the cotton pad $(10 \mu \mathrm{l}$ methylbutenol, $\approx 10 \mathrm{mg}$ cis-verbenol, $1 \mu \mathrm{l}$ ipsdienol, or $10 \mu \mathrm{l}$ verbenone). The glass jars were then filled with cotton pads, and so molecules in gas phase of each component passed passively by aeration transfer in the closed jar via adsorption of the odour to the pads placed above (Hudson-Holness and Furton 2010). The glass jars were stored in a freezer $(\approx-$ $\left.18^{\circ} \mathrm{C}\right)$.

For determination of release rates by GC-MS and corresponding dog training response (Fig. 1; Table 1), we always used the cotton pads from the top in each glass jar. The last five cotton pads in the glass jars were never used but filled up with new pads when needed. A cotton pad holding the semiochemical (Hudson-Holness and Furton 2010) was placed in a stainless steel tin ( $5 \mathrm{~cm}$ dia.) with perforated lids ('Ströare', Biltema ${ }^{\circledR}$, Helsingborg, Sweden). For release rates by GCMS and dog training response study, we prepared five steel tins of each synthetic pheromone at the same time. These tins were stored in room temperature $\left(\approx+20^{\circ} \mathrm{C}\right)$. Release rates were determined using odour collections similar to Zhang et al. (2000). An inverted glass funnel (5 cm dia.) was placed above the steel tin and air was drawn through a column packed with Porapak ( Q Q (25 mg mesh 60-80; in a Teflon tube $3 \mathrm{~mm}$ i.d.) at $100 \mathrm{ml} / \mathrm{min}$ at $15 \mathrm{~min}$ intervals (Photos and text ESM_0 in Johansson et al. (2019)). Compounds were eluted from the column with $400 \mu \mathrm{l}$ pentane (Sigma-Aldrich, Steinheim, Germany) into a $400-\mu l$ insert placed in a $2-\mathrm{ml}$ screw-top vial (Agilent Technologies, Böblingen, Germany), and $1 \mathrm{mg}$ heptyl acetate was added as internal standard. Aeration extracts were analysed by gas chromatographymass spectrometry (GC-MS; Agilent 6890-5975, Agilent Technologies, Santa Clara, CA, USA) with techniques previously reported (Birgersson et al. 1984). Quantifications were 

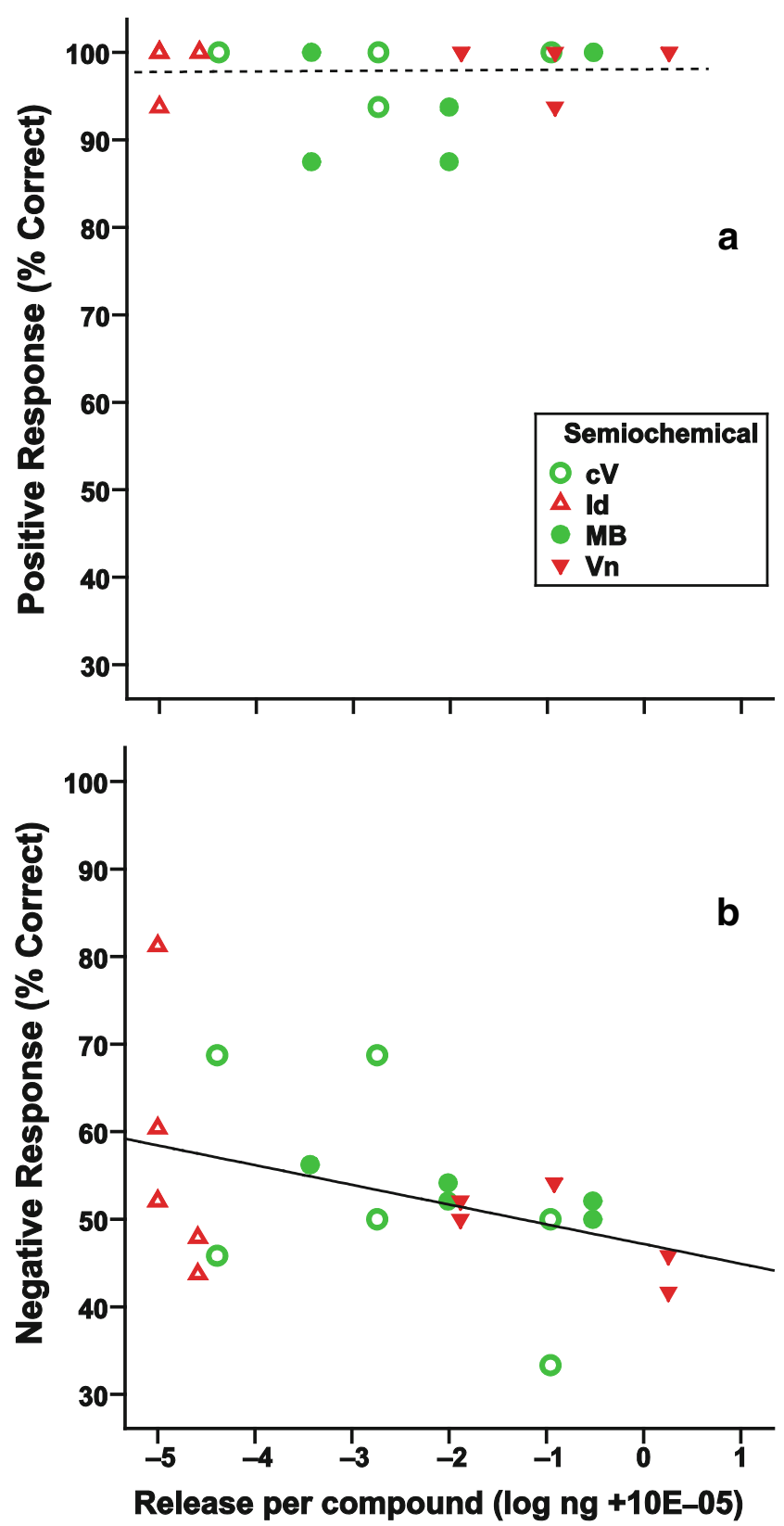

Fig. 1 Correct responses in relation to estimated stimuli evaporation rates. a Correct positive responses to stimuli (compounds) with estimated release rates per 15 min over 3 days of testing. No effect of time for all stimuli joined $\left(r^{2} \approx 0\right)$. b Correct negative responses to stimuli with known releases per 15 min over 3 days of testing. Weak effect of time for all stimuli joined $\left(r^{2}=0.18\right)$. Separately, MB shows the strongest effect $\left(r^{2}=0.85\right)$ followed by $\mathrm{Vn}\left(r^{2}=0.48\right)$. Chemical data from Table 1. The responses of the two dogs are pooled here, separate data in Supplementary Table (ESM_3 from Johansson et al. 2019). Semiochemical acronyms: MB, methylbutenol; cV, 4S-cis-verbenol; Id, Ipsdienol; Vn, (-)-verbenone

based on extracted ion chromatograms of prominent fragments for each tested compound and the internal quantification standard, respectively. The limit of quantification (LOQ) in the analytical procedure was $<0.1 \mathrm{ng} / \mathrm{min}$.

\subsection{Laboratory tests}

Initially, dog A was introduced to the bark beetle pheromones using the synthetic odour from a commercial dispenser, ETOpheron ${ }^{\circledR}$ (Pheronova AG, Switzerland), which is used in bark beetle monitoring traps. Because of the dispensers' construction of fabric with a plastic shell, it was not certain that the dog only learned the scent of the pheromone components as the target odour, or if it learned any other odour of the dispenser materials. One may inadvertently train a dog to detect an unexpected or impure source when attempting to train to a pure compound. To be sure that the dog learned the right odours, we subsequently trained the dog on pure synthetic semiochemicals applied to cotton pads (above). Non-target odours that could disturb search were also used in the training and consisted of items found in a forest setting such as vegetation odours from spruce needles, cones, resin, bark, moss, and animal odours (i.e. scent from feathers, fur, hoofs, and faeces). All non-target (disturbance) odours were collected in the forest or donated by local hunters (fur and hoofs from moose, deer, and boar). Both target and non-target odours were stored in jars of glass and transferred by aeration to cotton pads to ensure that the background odour of cotton was present in both target and disturbance odours.

The training platform used (Figure ESM_1 and video in ESM_4_V1 from Johansson et al. (2019)) was developed by Stig Meier Berg and Geir Kojedal, Spesialsøk, Selbu, Norway, based on an idea from Hundcampus, Hällefors, Sweden (Fischer-Tenhagen et al. 2011). It is designed to let the dog work independently, to minimise the cues from the handler, and to be easily manoeuvred by the handler creating a more effective learning situation with a high rate of opportunities to reward the dog for desired behaviour. Disturbance odours (non-target scents) were presented together with one or several target stimuli in a movable tray with seven positions (Figure A in ESM_2 from Johansson et al. (2019)). To compare different stimulus linear layouts, mixing target and nontarget scent, on the movable tray, the two dogs were tested in three trials with each stimulus layout.

For evaluation of the dog detection performance with decreasing amounts of odour molecules over time, nine trials were conducted to evaluate the dogs' identification performance with each synthetic semiochemical. For these trials, we used four of the prepared five steel tins containing cotton pads with synthetic semiochemical. Since the trials were conducted over several days (1-84 $\mathrm{h}$ after the cotton pads were placed in the tins and stored in room temperature), we used a new tin every day. This was done to make sure that the tins were not contaminated with any other scents such as odour from the dogs. Every trial session lasted for approximately $1 \mathrm{~min}(50-70 \mathrm{~s})$. 


\subsection{Outdoor tests}

To train the dogs to pinpoint the target odour source outdoors, pieces of the cotton pads containing synthetic pheromone odours as those used for platform training were hidden in cracks of the bark of several species of trees. The cotton pieces were placed in the height of the nose of the dogs and the dogs were shown where to sniff for the target (video ESM_4_V2 from Johansson et al. (2019)). When the dog found the cotton piece holding the target odour, it was immediately rewarded by a clicker sound and a piece of food delivered between its nose and the odour source. Several pieces of cotton with either target or non-target odours were put in cracks of the bark in a small area $(30 \times 30 \mathrm{~cm})$ to ensure the dogs did not use visual cues for close-range target location. When the dog understood the game, consistently $(\sim 100 \%)$ locating the pads, the height of the placement was gradually increased up to $1 \frac{1}{2} \mathrm{~m}$ aboveground and only cotton pads with target odour were used. The dog was sent from longer distances to locate the tree in which the cotton pad was put. Because the cotton pads contain very low concentrations of the synthetic substance and emit very little odour, the pads were replaced with commercial dispensers as the dog became more skilled for the task. The fresh dispensers used in traps emit several orders of magnitude odour molecules than pads and for a longer period of time. By using the dispensers, the dog could recognise the target odour from a greater distance and must practise its search technique while working its way upwind in the vapour plume towards the source.

Dogs were trained in the winter under a variety of weather conditions (e.g. rain, snow, sun).

Training trials using synthetic odour were conducted on average once a week during 2009 and 2010. The temperature ranged from 2 to $28{ }^{\circ} \mathrm{C}$. The handler determined the search strategy to best cover the assigned area based on wind conditions and terrain. These protocols were employed to simulate future practical field survey conditions.

A first proof-of-concept test, evaluating the detection by dogs of spruces that were known to be recently attacked by bark beetles, was conducted at the Nature Reserve of Notteryd (near Växjö, Småland, Sweden). The area consisted of windfelled trees and standing healthy spruces. In the spring of $2009,95 \%$ of all spruces in the reserve were already killed by bark beetles. The remaining spruces that were still alive stood together in clusters of 10-15 trees. We felt these circumstances made this particular Nature Reserve an optimal area to first try the dogs on natural attacks. Another series of tests were conducted at a production-forest in Nottebäck, also near Växjö, Småland, Sweden, with the permission of the owner of the forest. The dog team consisted of one $\operatorname{dog}(\operatorname{dog} A)$ working off-leash and one handler and searched three different 
areas in the production forest attacked by bark beetles in previous years. The handler had knowledge of the location of former attacks, but no information on new attacks. The dog and handler searched each area with no time limit. The handlers determined their search strategy to best cover the assigned area based on wind and terrain. These protocols were employed to simulate expected future practical field survey conditions.

Dog and handler movements were recorded using global positioning systems (GPS) in 5-s intervals in all field trials. These data allowed identification of the point at which the dogs lifted their nose up in the air and made a sudden change in direction of travel and moved directly towards an infested spruce (video of search using GPS; ESM_4_V3 from Johansson et al. (2019)). The GPS units used in the study were Garmin Astro® 220 Nordic handset and Garmin DC30 dog collar (Garmin Corporation, Taiwan). The map used in the handset was Garmin 'Friluftskartan Pro V2 Götaland'. The data from the GPS unit were transferred to a PC with Garmin's software MapSource. Using the measuring tool, we could measure the distance from where a track from the dog changed direction to the waypoint where the dog alerted on an infested spruce.

\subsection{Field trial—detection distance from natural sources}

We used 20 different areas, whereof 10 were located in nature reserves and 10 in production forests, with permission of the owners and from The Swedish Forest Agency in Växjö in 2010. All areas were 2-4 ha and tests were done in three different set-ups: (a) 10 search areas with location of infestations known by handler, (b) 5 areas with location of infestations known by the forest manager, and (c) 5 areas with location of infestations unknown, but were considered as risk areas with bark beetles' infestations on previous seasons.

To design the best search strategy for long distance detection, based on wind, terrain, and the location of the attacks, the dog handler had prior knowledge of attacks in the 10 first areas. To estimate if the dog handler might involuntarily cue the dog to an odour source (an infested tree), the dog handler was not allowed prior knowledge of attacks in the 10 latter areas.

\section{Results}

\subsection{Laboratory training}

The two dogs were successfully trained to recognise the four different synthetic semiochemical compounds on the educational scent platform (video ESM_4_V1 from Johansson et al. (2019)). Both dogs learned to recognise a new target scent in just one training trial, similar to Johnston (1999). In that time, the dogs managed to sample the tins for target odour about 30 times on average. Occasionally, the dogs reacted with an increased interest when a new non-target disturbance odour was presented. When this happened, the handler stood silent and just waited until the dog stopped investigating the new non-target odour and, if the dog did not continue to search by itself, gave the dog a new command to start sampling the other tins again. After a few encounters with the new nontarget odour, the dogs' interest decreased since they learned that there would not be any reward for that particular odour. Even though the dogs were interested in new disturbance odours (mostly edible items like cookies and chips or scents from other animals), the handler did not record such behaviour as an alert. When alerting on a target odour, both dogs stopped sampling, and waited for their reward, in contrast to increased sampling a tin in order to investigate a disturbance odour.

\subsection{Chemical stimulus strength}

Chemical quantification by odour collection and GC-MS was at start routine with a limit of quantification (LOQ) of $<$ $0.1 \mathrm{ng} / \mathrm{min}$. However, 2 days later, we found that most stimuli titres, still well biologically active, decreased to below the LOQ. Using estimates based upon linear regression, chemical data indicates that by the third day, some compounds were very close to zero (Table 1).

The dogs responded to estimated doses of $10^{-4} \mathrm{ng} / 15 \mathrm{~min}$ releases or less. The four different semiochemicals were learned equally well, and responses to these sub-picogram release rates of stimuli aged up to 3.5 days remained stable (Table in ESM_3 from Johansson et al. 2019).

\subsection{Biological responses}

The responses of both dogs to target odours are summarised per target scent in the Supplementary Table (ESM_3 from Johansson et al. (2019)). The dogs achieved a mean of $99 \%$ correct indications; $1 \%$ of the incorrect indications were either false positive (alerting to a non-target odour; $\operatorname{dog}$ A) or false negatives at the beginning of a trial session (dog B). None of the dogs sampled all tins in every repetition. In each repetition, four tins were presented, but the trainer could never know where the dog would start searching or in which direction it would continue its search. The only dispenser tin always sampled was the tin holding the target scent. This explains the high success rate of $99 \%$ for correct positives for the target scent (at which tin the search will stop), but the much lower rate, $55 \%$ for the correct negatives with direct sampling of empty tins before finding the target scent. 
To increase the dogs sampling of all presented tins, we tried the dogs in different kinds of stimulus layouts with zero to three different target odours presented in the same trial (Figure A in ESM_2 from Johansson et al. (2019)). The only clear effect was for the layout with no target scent, where response decreased with time (Figure B in ESM_2 from Johansson et al. (2019)). Other sample set-ups and target scents had correct positives close to $100 \%$ (Table 2).

Interestingly, over the $>3$ days of testing combined with chemical sampling, the correct responses remained consistently high irrespective of compound (Table in ESM_3 from Johansson et al. (2019)). The positive responses showed no decline with estimated chemical stimulus levels (Fig. 1a), indicating that stimulus levels were above the animal detection limit for the whole duration of the testing period. The correct negative responses (no alert to tins with disturbance odours) declined with the estimated stimulus strength, likely since the dogs learned that these odours were not going to be rewarded (Fig. 1b).

\subsection{Outdoor tests}

During off-season training, dogs were introduced to cotton pads initially placed at nose height in the cracks of the bark in different kinds of trees (Video ESM_4_V2 from Johansson et al. (2019)). Dog A, previously trained as a search and rescue dog, just needed to come into contact with one of the newly learned target odours to expect a reward, hence follow it to the source and pinpoint it to its handler. Dog A also alerted the found target source by barking. This was the trained alert when locating a hidden human as a search and rescue dog. Dog B, however, which had no previous search training, had to learn how to follow the odour plume to the source. Dog B was not trained to perform any other alert than pinpointing the source of the target odour. This dog did not know any other way to receive its reward but putting its nose on the target source. The target source became a button to push to get its reward.

Bark beetle activity began at the end of April, when the temperature increased to over $20{ }^{\circ} \mathrm{C}$, allowing us to test the dogs' ability to detect natural pheromone from attacking spruce bark beetles. Dog A successfully found the first spruce that was under attack, on the first day. The spruce in question showed no signs of the attack at first sight, but further inspection at close range revealed that the first bark beetles were drilling their way into the spruce bark and the sound of their drilling could also be heard. This finding was crucial in demonstrating that it is possible to train a dog on a synthetic odour and subsequently showing that it will alert to the natural odour under field conditions. All training of beetle detection in the Nature Reserve was terminated at the end of May when so many spruces were under various phases of bark beetle attack that the smell from the attacked trees became obvious even for the human nose.

Table 2 Evaluation of correct indications in different sample set ups with stimuli and blanks

\begin{tabular}{|c|c|c|c|c|c|c|c|c|c|}
\hline \multirow[t]{2}{*}{ Dog ID } & \multirow[t]{2}{*}{ Sample set-up ${ }^{1}$} & \multirow[t]{2}{*}{ Target scent } & \multirow{2}{*}{$\begin{array}{l}\text { Response type } \\
(n / \text { trial })\end{array}$} & \multicolumn{3}{|c|}{ Stimuli age } & \multicolumn{3}{|c|}{ Correct indications } \\
\hline & & & & \multicolumn{4}{|c|}{ Number of indications } & $\%$ & $\begin{array}{l}\text { Mean } \\
\text { both dogs }\end{array}$ \\
\hline \multirow[t]{2}{*}{ A } & \multirow[t]{4}{*}{1} & \multirow[t]{4}{*}{ Methylbutenol } & $\mathrm{CPa}(16)$ & 16 & 16 & 16 & 48 & 100 & \\
\hline & & & $\mathrm{CN}(48)$ & 32 & 28 & 31 & 91 & 63 & \\
\hline \multirow[t]{2}{*}{ B } & & & CP (16) & 13 & 16 & 16 & 45 & 94 & $97 \%$ \\
\hline & & & $\mathrm{CN}(48)$ & 30 & 27 & 29 & 86 & 60 & $61 \%$ \\
\hline \multirow[t]{2}{*}{ A } & \multirow[t]{4}{*}{$2 \mathrm{a}$} & \multirow[t]{4}{*}{ Methylbutenol and cis-verbenol } & $\mathrm{CP}(12+12)$ & 24 & 20 & 23 & 67 & 93 & \\
\hline & & & $\mathrm{CN}(40)$ & 23 & 18 & 17 & 58 & 48 & \\
\hline \multirow[t]{2}{*}{ B } & & & $\mathrm{CP}(12+12)$ & 23 & 21 & 22 & 66 & 92 & $92 \%$ \\
\hline & & & $\mathrm{CN}(40)$ & 17 & 14 & 22 & 53 & 44 & $46 \%$ \\
\hline \multirow[t]{2}{*}{ A } & \multirow[t]{4}{*}{$2 b$} & \multirow[t]{4}{*}{ Ipsdienol and verbenone } & $\mathrm{CP}(8+8)$ & 16 & 16 & 16 & 48 & 100 & \\
\hline & & & $\mathrm{CN}(48)$ & 47 & 44 & 36 & 127 & 88 & \\
\hline \multirow[t]{2}{*}{ B } & & & $\mathrm{CP}(8+8)$ & 16 & 16 & 16 & 48 & 100 & $100 \%$ \\
\hline & & & $\mathrm{CN}(48)$ & 43 & 28 & 31 & 102 & 71 & $80 \%$ \\
\hline \multirow[t]{2}{*}{ A } & \multirow[t]{4}{*}{3} & \multirow[t]{4}{*}{ cis-Verbenol, ipsdienol, and verbenone } & $\mathrm{CP}(4+16+4)$ & 23 & 22 & 24 & 69 & 96 & \\
\hline & & & $\mathrm{CN}(40)$ & 37 & 40 & 33 & 110 & 92 & \\
\hline \multirow[t]{2}{*}{ B } & & & $\mathrm{CP}(4+16+4)$ & 24 & 22 & 24 & 70 & 97 & $97 \%$ \\
\hline & & & $\mathrm{CN}(40)$ & 31 & 36 & 32 & 99 & 83 & $87 \%$ \\
\hline
\end{tabular}

${ }^{1}$ Arrangement of positive (target) and disturbance (non-target) stimuli, see Figure A in ESM_2 (Johansson et al. (2019))

$C P$, correct positive; $C N$, correct negative 
Both dogs were also successful in locating sparser attacks in production forest stands, where attacks were known neither to the dog handler nor to the forest manager. In the first area searched, $\operatorname{dog}$ A detected and alerted to a single, wind-felled spruce that had been infested by bark beetles. In the second area searched, the same dog found seven infested standing spruces. Five of them stood together in a cluster among old attacks. Two were located in a felling edge.

In the third area, the dog detected five infested spruces, both standing and wind-felled. In this area, all the spruces were located near a felling edge by a clear-felled area where felled trap-trees were placed. The dog started its search with detecting and alerting on the synthetic pheromones from the trap-trees. When sent to continue its search, the dog detected, recognised, followed, and alerted on the natural pheromones emitted from the bark beetles in standing trees (as shown in video ESM_4_V4 from Johansson et al. (2019)).

Quantitatively, the handler measured by GPS that a majority of successfully located sources of natural pheromone were detected within $50 \mathrm{~m}$, but both dogs located sources in a behavioural sequence over a range of 50-100 m (Fig. 2a). No differences in detection distance by GPS could be seen among areas with attacks (10) known or unknown (10) to the handler. Later analysis of the GPS tracks showed seven cases where the more experienced $\operatorname{dog}$ A changed direction and was able to detect the pheromones from bark beetle-attacked trees at a distance of over $100 \mathrm{~m}$ (Fig. 2b). In the 20 areas visited, the dogs found in total 193 trees infested by bark beetles in 77 different groups of attacked trees.

\section{Discussion}

Training canines to detect bark beetle-infested trees poses some important limitations, including the relatively short season available for using trees at various stages of attack, as well as the risk of inducing a full-blown tree attack by placing pheromone for training purpose on a host tree during the actual beetle flight period. While it is probably possible to train a detection dog to locate spruces that have been attacked by bark beetles by just letting the dog sniff an attacked spruce and reward the dog, such a 'natural' method will not teach a dog to recognise the different kinds of semiochemicals the bark beetle releases over the course of an attack. Therefore, we chose to train the dogs to recognise a series of synthetic pheromone compounds using an indoor training platform. In this study, we demonstrate that canines trained on synthetic bark beetle pheromone compounds at low (sub-picogram) levels, indoors, can later recognise naturally produced pheromone over long distances, outdoors. Additionally, by using synthetic sources of the bark beetle pheromone in the laboratory, it is possible to train dogs off-season long before the bark beetles start their flight period in the field, and the dog handler has control over which odours the dog learns, one at a time and at very low concentrations. The indoor training of canines also has the benefit in that other environmental distractions are minimised, thereby allowing the dogs to concentrate on and learn the target odours.

In the field, detection dogs that work over large areas ('offleash') can often be seen lifting their nose up in the air and then make a sudden change in direction of travel. This likely occurs when the dog enters an area with a detectable odour (a plume) that the dog identifies as its trained target odour, while the odour plume structure in a field setting, where the plume shape, size, and persistence are highly dynamic, cannot be easily delineated by chemical means due to the very low titres present in open air (Murlis et al. 2000; Riffell et al. 2008). It can, however, be indirectly observed through olfactorybehavioural responses of animals to target odour plumes. In our study, a trained detection dog could detect an infested spruce tree from a distance of $150 \mathrm{~m}$, which is farther away than that estimated for bark beetles (Ips typographus) responding to beetle pheromone dispensers (Schlyter 1992).

In training dogs to detect bed bugs (Cimex lectularius L.), the dog usually searches (either 'on-leash' or 'off-leash') the entire room - often several times - before alerting on a bed bug. In this case, the dog handler interaction is paramount owing to the vastly different scales of indoor room searches (1-10 m) compared with free-ranging forest searches (10 $500 \mathrm{~m})$. Issues surrounding a close interaction between dog and handler have been reported (Lit et al. 2011), though during our large-scale forest searches, these issues would be minimal, at best. In a study of canines involved in bed bug detection, a high degree of both false positives and low true positives were found (Cooper et al. 2014).

Little, if any, studies can be found using pure, known synthetic samples for canine detection purposes (Johnen et al. 2013). However, it is clear that canines can show a doseresponse to relatively low (but quantitatively unknown) doses (Krestel et al. 1984; Polgár et al. 2016; Walker et al. 2006). Our levels of correct positives (sensitivity) and correct negatives (specificity) appear high, compared to the seven studies recently reviewed that provided such data (Johnen et al. 2013). Hitherto, no quantitative data exist on chemical strength during dog training in the open literature in spite of some early attempts (Krestel et al. 1984; Walker et al. 2006). No doubt, the dearth of chemical data is due to low thresholds for dog response to volatiles. While our data are novel, we must admit that our empirical data spans only a part of the tested range of stimuli diminution over time, mainly the 1-day-old dispenser material, and we had to rely on estimates from linear regression for the older material with lower releases. Still, our estimates appear to be the best so far documented.

The 'search-and-pick' method of detection and removal by 'sanitation cutting' of bark beetle-infested trees within 2-3 weeks of attack (Svensson 2007) often fail because of 
Fig. 2 Field GPS tracks and dog detection distances. a Tracks from an example of handler and search dog finding a small group of unknown mass-attacked trees. GPS unit track shown with Google Earth background satellite image over the area. Distance from Change of Direction to the attacked trees $=158 \mathrm{~m}$ (distance and tracks by BaseCamp ${ }^{\mathrm{TM}}$, ver. 4.7.0, Garmin Ltd). Maps, aerial photos/satellite images:

Copyright/Lantmäteriet, Sweden, consent \#: I2011/0096 (see dog search and GPS unit tracking in video ESM_4_V3 from Johansson et al. (2019)). b Detection distances (distance from Change of Direction to the attack) recorded from GPS tracks (as above) when locating natural bark beetle mass attacks unknown to handler
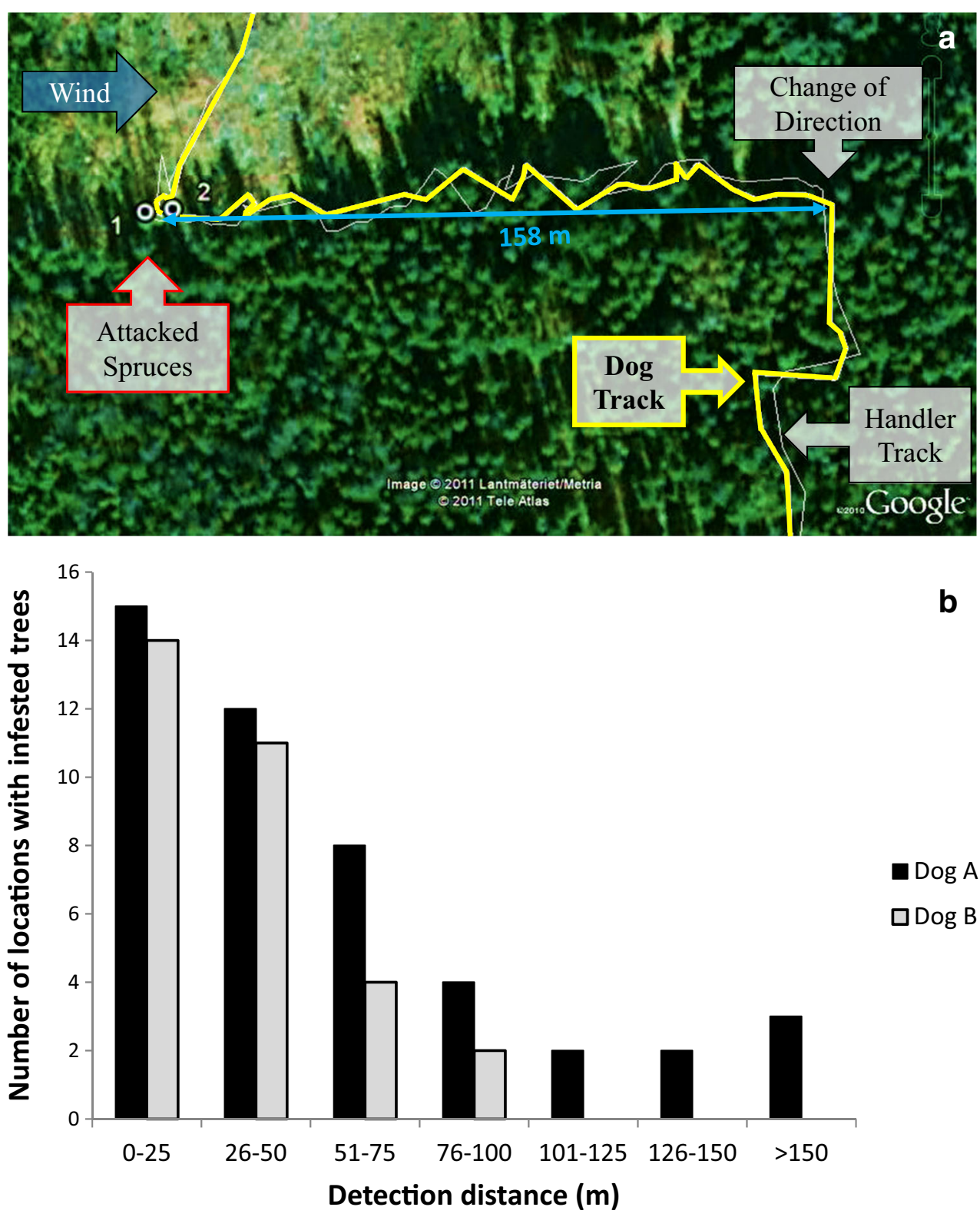

Dog A

$\square \operatorname{Dog} B$ the short time frame involved. Trees were often not cut and removed from the forest until weeks or months later by 'salvage cutting' (Långström and Björklund 2010), long after beetles had moved to attack other trees. Finding spruces in an early stage of attack is also significant for the timber value, due to a blue stain fungi the beetle introduces into the newly attacked trees (Kirisits 2004).

Since the pheromone blends used by the bark beetles for intraspecific communication vary in strength and composition over time, we importantly observed that the dogs could detect all of the substances on which they were trained; therefore, it makes no difference which semiochemical composition the bark beetles in an infested tree is currently emitting. Thus, a trained dog will detect and follow any of the odours, alone or in blends, to the source and alert the dog handler. While the dog may learn additional odours that may occur when a spruce is under attack (Birgersson and Bergström 1989; Schiebe et al. 2012), any conclusions to this effect would be speculation on our part.

In our study, searches would often be conducted in colder and wetter periods, in-between the short warmweather swarming periods of the beetle. It would be interesting and of practical relevance to know more precisely how different weather conditions may affect the dogs' ability to search a larger area (Soroker et al. 2017). Another question of considerable practical importance, but not tested in this first study, is if endemic vs. epidemic contexts would affect the detection accuracy of doghandler pairs. Later experiences by us indicate that such pairs are able to orient in stands very heavily attacked as 
well as to find single-attacked trees (Johansson et al. unpubl.). Dogs may as well in practical search orient to pheromone in traps. For the dog, both a trap and an attacked tree are trained target sources and are correspondingly correct positive responses. The dog does not distinguish between the two. For the dog, it is just a source that means reward from the handler. Similarly, one may ask what amount of stand surface that could be inspected per day, but this cannot be quantified from the present data. Detection of attacks higher up on the trunk is another challenge; we have observed that a motivated and experienced dog can handle such situations. A direct comparison to detection by humans alone is difficult to do here, as high attacks are seen only very late when the crown fades.

In view of the large number of pheromones identified to date from moths, beetles, and other pests (>1000) (El-Sayed 2019), it would seem feasible to start training detection dogs for many pest management systems.

\section{Conclusion}

This is the first report of using synthetic pheromone compounds at known titres to train detection dogs to detect and locate living animals in the field. Dogs could detect and locate the source of pest insect infestations at a distance of over $100 \mathrm{~m}$ or more. The use of detection dogs for early detection of bark beetle infestations could contribute to better forest protection by timely sanitation felling. We suggest that, in general, use of stimuli that are biochemically well-defined in both quality and quantity appears to hold promise for both better practise and science in detection dog training to biological objects, such as cryptic woodborer pests.

Acknowledgments We thank Drs. M. Andersson and A. Bonaventura, and Prof. O. Anderbrant, as well as Drs. Veronique Martel and Krista Ryall, and Mr. T. Gustafsson for valuable comments on earlier versions. Special thanks to go to Dr. M. Feldlaufer (USDA, Beltsville) for extensive suggestions on content and language. The authors thank A. Holmström at The Swedish Forest Agency, Växjö, and the private foresters for granting us access to field trial and search areas in nature reserves and production forests.

Funding information This research was funded by two grants from 'The Södra Foundation for Research, Development and Education', Växjö, Sweden, to AJ. FS and GB was supported by the Linnaeus programme 'Insect Chemical Ecology, Ethology and Evolution' (IC-E $E^{3}$, \#217-20061750 ) at SLU and later to FS ('Rapid olfactory detection of insect and fungal damage in forests', \#2013-1583) both from 'The Swedish Research Council Formas'. FS was further supported by EXTEMIT-K project financed by OP RDE at Czech University of Life Sciences Prague (CZ.02.1.01/0.0/0.0/15-003/0000433).

Data availability The datasets generated and/or analysed during the current study are available in the Zenodo repository (Johansson et al. 2019) at https://doi.org/10.5281/zenodo.2605357.

\section{Compliance with ethical standards}

Conflict of interest The authors declare that they have no conflicts of interest.

Statement on ethical approval All applicable Swedish ethic guidelines for the care and use of animals were followed. Both dogs participating in this study were privately owned working dogs and handled by their owners.

Disclaimer Funding sources were not involved in study design, data collection/interpretation, or writing/submission of this report.

Open Access This article is distributed under the terms of the Creative Commons Attribution 4.0 International License (http:// creativecommons.org/licenses/by/4.0/), which permits unrestricted use, distribution, and reproduction in any medium, provided you give appropriate credit to the original author(s) and the source, provide a link to the Creative Commons license, and indicate if changes were made.

\section{References}

Andersson MN, Schlyter F, Hill SR, Dekker T (2012) What reaches the antenna? How to calibrate odor flux and ligand-receptor affinities. Chem Senses 37:403-420. https://doi.org/10.1093/chemse/bjs009

Beebe SC, Howell TJ, Bennett PC (2016) Using scent detection dogs in conservation settings: a review of scientific literature regarding their selection. Front Vet Sci 3:96. https://doi.org/10.3389/fvets.2016.00096

Birgersson G, Bergström G (1989) Volatiles released from individual spruce bark beetle entrance holes: quantitative variations during the first week of attack. J Chem Ecol 15:2465-2483. https://doi. org/10.1007/BF01020377

Birgersson G, Schlyter F, Löfqvist J et al (1984) Quantitative variation of pheromone components in the spruce bark beetle Ips typographus from different attack phases. J Chem Ecol 10:1029-1055. https:// doi.org/10.1007/BF00987511

Brooks SE, Oi FM, Koehler PG (2003) Ability of canine termite detectors to locate live termites and discriminate them from non-termite material. J Econ Entomol 96:1259-1266. https://doi.org/10.1603/00220493-96.4.1259

Browne C, Stafford K, Fordham R (2006) The use of scent-detection dogs. Ir Vet J 59:97-104

Cooper R, Wang C, Singh N (2014) Accuracy of trained canines for detecting bed bugs (Hemiptera: Cimicidae). J Econ Entomol 107: 2171-2181. https://doi.org/10.1603/EC14195

El-Sayed A (2019) The Pherobase: database of pheromones and semiochemicals. http://www.pherobase.com. Accessed 2019-01-29

Fischer-Tenhagen C, Wetterholm L, Tenhagen BA, Heuwieser W (2011) Training dogs on a scent platform for oestrus detection in cows. Appl Anim Behav Sci 130:63-70. https://doi.org/10.1016/j. applanim.2011.01.006

Goodwin KM, Engel RE, Weaver DK (2010) Trained dogs outperform human surveyors in the detection of rare spotted knapweed (Centaurea stoebe). Inv Plant Sci Manag 3:113-121

Grégoire J-C, Evans HF (2004) Damage and control of Bawbilt organisms - an overview. In: Lieutier F, Day KR, Battisti A, Grégoire J-C, Evans HF (eds) Bark and wood boring insects in living trees in Europe, a synthesis. Springer, Netherlands, pp 19-37. https://doi. org/10.1007/978-1-4020-2241-8 4

Hepper P, Wells D (2015) Olfaction in the order Carnivora: family Canidae. In: Doty RL (ed) Handbook of olfaction and gustation. John Wiley \& Sons, Inc, Hoboken, NJ, pp 591-604. https://doi. org/10.1002/9781118971758.ch26 
Hoyer-Tomiczek U, Sauseng G, Hoch G (2016) Scent detection dogs for the Asian longhorn beetle, Anoplophora glabripennis. EPPO Bull 46:148-155. https://doi.org/10.1111/epp.12282

Hudson-Holness D, Furton K (2010) Comparison between human scent compounds collected on cotton and cotton blend materials for SPME-GC/MS analysis. J Forensic Res 1:101. https://doi.org/10. 4172/2157-7145.1000101

Johansson A, Birgersson G, Schlyter F (2019) Data for paper "Using synthetic semiochemicals to train canines to detect bark beetleinfested trees" in Ann For Sci. [Dataset]. V3. Zenodo. https://doi. org/10.5281/zenodo.2605357 Accessed 1 April 2019

Johnen D, Heuwieser W, Fischer-Tenhagen C (2013) Canine scent detection - fact or fiction? Appl Anim Behav Sci 148:201-208. https:// doi.org/10.1016/j.applanim.2013.09.002

Johnston J (1999) Canine detection capabilities: operational implications of recent R \& D findings. http://www.barksar.org/K-9_Detection Capabilities.pdf. Accessed 2017-02-23

Kirisits T (2004) Fungal associates of European bark beetles with special emphasis on the ophiostomatoid fungi. In: Lieutier F, Day KR, Battisti A, Grégoire J-C, Evans HF (eds) Bark and wood boring insects in living trees in Europe, a synthesis. Springer, Netherlands, pp 181-236. https://doi.org/10.1007/978-1-4020-2241-8 10

Krestel D, Passe D, Smith J et al (1984) Behavioral determination of olfactory thresholds to amyl acetate in dogs. Neurosci Biobehav Rev 8:169-174. https://doi.org/10.1016/0149-7634(84)90037-X

Långström B, Björklund N (2010) Progress in management of spruce bark beetle [In Swedish: Så har bekämpningen av granbarkborren lyckats]. http://pub-epsilon.slu.se:8080/1693/ (PDF in permanent archive of SLU) Accessed 2018-12-05

Leufvén A, Birgersson G (1987) Quantitative variation of different monoterpenes around galleries of Ips typographus (Coleoptera: Scolytidae) attacking Norway spruce. Can J Bot 65:1038-1044

Lit L, Schweitzer JB, Oberbauer AM (2011) Handler beliefs affect scent detection dog outcomes. Anim Cogn 14:387-394. https://doi.org/ 10.1007/s10071-010-0373-2

Lorenzo N, Wan TL, Harper RJ, Hsu YL, Chow M, Rose S, Furton KG (2003) Laboratory and field experiments used to identify Canis lupus var. familiaris active odor signature chemicals from drugs, explosives, and humans. Anal Bioanal Chem 376:1212-1224

Mosconi F, Campanaro A, Carpaneto GM, Chiari S, Hardersen S, Mancini E, Maurizi E, Sabatelli S, Zauli A, Mason F, Audisio P (2017) Training of a dog for the monitoring of Osmoderma eremita. Nat Conserv 20: 237-264. https://doi.org/10.3897/natureconservation.20.12688

Murlis J, Willis MA, Cardé RT (2000) Spatial and temporal structures of pheromone plumes in fields and forests. Physiol Entomol 25:211222. https://doi.org/10.1046/j.1365-3032.2000.00176.x

Nakash J, Osem Y, Kehat M (2000) A suggestion to use dogs for detecting red palm weevil (Rhynchophorus ferrugineus) infestation in date palms in Israel. Phytoparasitica 28:153-155. https://doi.org/10. 1007/BF02981745

Pfiester M, Koehler PG, Pereira RM (2008) Ability of bed bug-detecting canines to locate live bed bugs and viable bed bug eggs. J Econ Entomol 101:1389-1396
Polgár Z, Kinnunen M, Újváry D, Miklósi Á, Gácsi M (2016) A test of canine olfactory capacity: comparing various dog breeds and wolves in a natural detection task. PLoS One 11:e0154087. https://doi.org/ 10.1371/journal.pone.0154087

Riffell J, Abrell L, Hildebrand JG (2008) Physical processes and real-time chemical measurement of the insect olfactory environment. J Chem Ecol 34:837-853

Schiebe C, Hammerbacher A, Birgersson G, Witzell J, Brodelius PE, Gershenzon J, Hansson BS, Krokene P, Schlyter F (2012) Inducibility of chemical defences in Norway spruce bark is correlated with unsuccessful mass attacks by the spruce bark beetle. Oecologia 170:183-198 DOI. https://doi.org/10.1007/s00442-0122298-8

Schlyter F (1992) Sampling range, attraction range, and effective attraction radius: estimates of trap efficiency and communication distance in coleopteran pheromone and host attractant systems. J Appl Entomol 114:439-454. https://doi.org/10.1111/j.1439-0418.1992. tb01150.x

Schlyter F, Byers J, Löfqvist J (1987) Attraction to pheromone sources of different quantity, quality, and spacing: density-regulation mechanisms in bark beetle Ips typographus. J Chem Ecol 13:1503-1523. https://doi.org/10.1007/BF01012294

Schlyter F, Birgersson G, Leufvén A (1989) Inhibition of attraction to aggregation pheromone by verbenone and ipsenol: density regulation mechanisms in bark beetle Ips typographus. J Chem Ecol 15: 2263-2278. https://doi.org/10.1007/BF01014114

Soroker V, Suma P, La Pergola A et al (2017) Surveillance techniques and detection methods for Rhynchophorus ferrugineus and Paysandisia archon. In: Handbook of major palm pests: biology and management, pp 209-232. https://doi.org/10.1002/9781119057468.ch10

Suma P, La Pergola A, Longo S et al (2014) The use of sniffing dogs for the detection of Rhynchophorus ferrugineus. Phytoparasitica 42: 269-274. https://doi.org/10.1007/s12600-013-0330-0

Svensson L (2007) Övervakning av insektsangrepp - Slutrapport från Skogsstyrelsens regeringsuppdrag [In Swedish: Monitoring of insect attacks - Final report from SFA's government assingment]. Swedish Forest Agency. http://shop.skogsstyrelsen.se/shop/9098/ art73/4645973-904329-1557-1.pdf. Accessed 03 May 2019

Vaidyanathan R, Feldlaufer MF (2013) Bed bug detection: current technologies and future directions. Am J Trop Med Hyg 88:619-625. https://doi.org/10.4269/ajtmh.12-0493

Walker DB, Walker JC, Cavnar PJ, Taylor JL, Pickel DH, Hall SB, Suarez JC (2006) Naturalistic quantification of canine olfactory sensitivity. Appl Anim Behav Sci 97:241-254. https://doi.org/10.1016/j. applanim.2005.07.009

Zhang Q-H, Schlyter F, Birgersson G (2000) Bark volatiles from nonhost angiosperm trees of spruce bark beetle, Ips typographus (L.) (Coleoptera: Scolytidae): chemical and electrophysiological analysis. Chemoecol 10:69-80. https://doi.org/10.1007/s000490050010

Publisher's note Springer Nature remains neutral with regard to jurisdictional claims in published maps and institutional affiliations. 